Part of Journal of Research of the National Bureau of Standards, Volume 29, July 1942

\title{
ELASTICITY OF WOOL AS RELATED TO ITS CHEMICAL STRUCTURE
}

\author{
By Milton Harris, Louis R. Mizell, and Lyman Fourt ${ }^{1}$
}

\section{ABSTRACT}

Wool protein, like other fibrous proteins, is composed of long, flexible molecular chains. This flexibility appears to be the basis of the "long-range" elasticity of wool fibers. The wool fiber is distinguished from other textile fibers by the presence of covalent disulfide cross-links between these main chains. Rupture of these links by chemical means decreases the strength of the fiber without necessarily affecting the elastic recovery. Rebuilding the covalent linkages largely restores the original properties of the fiber.

Wool appears to be analogous to rubber in several respects. Thus the stressstrain, solubility, and swelling characteristics are greatly influenced by the extent of cross-linking in the two materials.

\section{CONTENTS}

I. Introduction

II. Molecular structure of wool

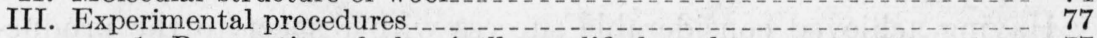

1. Preparation of chemically modified wools

2. Determination of elasticity $\ldots$

IV. Elastic behavior of wool and chemically modified wools

V. Analogy between wool and rubber . _ . 81

VI. Conclusion

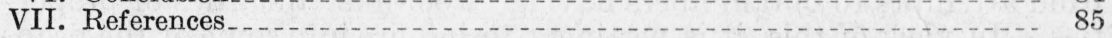

\section{INTRODUCTION}

The earlier efforts of those engaged in research on textile fibers, and more especially the regenerated or synthetic fibers, were principally devoted to increasing their strengths. It is a matter of history that the first regenerated fibers were so weak, especially in the wet state, that they were considered by many to be a passing fad. The progress that has been made in the interim is well known; the strengths of many of these fibers have been increased to the point where they exceed the demands of many of the purposes for which they are now used.

This progress has resulted from numerous investigations, and in this connection, the early observations by Scherrer $[1]^{2}$ and by Herzog and Jancke [2] on ramie, and later by Meyer and Mark [3], Astbury and his collaborators [4], and others, that the fibers show a predominant, preferred orientation, in which the molecules are alined more or less parallel to the axis of the fiber, were extremely helpful. The results of these investigations lead to the concept that fibrous materials, in spite of their lack of homogeneity and their high mole-

\footnotetext{
1 Research Associates at the National Bureau of Standards, representing the Textile Foundation.

2 Figures in brackets indicate the literature references at the end of this paper.
} 
cular weights, are not necessarily amorphous but show a definite crystallizing tendency, in that portions of the fiber apparently consist of compact bundles of long-chain molecules in a parallel arrangement. On the basis of this concept, it has been possible to explain many facts concerning the structure and strength of high-polymers in general and of the fibers in particular. For example, for a given fiber it has been frequently shown that the strength is directly related to the degree of orientation; that is, the more highly oriented the crystallites of the fiber the higher the strength. While it is recognized that other factors, such as molecular chain length and the nature of the intermolecular forces, also have a profound influence on the strength of fibers, it can be shown that in a general way the strengths of entirely different classes of fibers are comparable on the same basis. The data in table 1 illustrate this point.

TABLE 1.-Comparison of different classes of fibers

\begin{tabular}{|c|c|c|}
\hline Fiber & Relative degree of "crystallinity" & Breaking strength \\
\hline $\begin{array}{l}\text { Flax } \\
\text { Ramie- } \\
\text { Nylon-- } \\
\text { Cotton- } \\
\text { Rayons }{ }^{1}- \\
\text { Silk } \\
\text { Wool }\end{array}$ & $\begin{array}{l}\text { Very high } \\
\text { High } \\
\text { Medium } \\
\text { Low to high } \\
\text { Medium } \\
\text { Low }\end{array}$ & $\begin{array}{c}\text { lb./in. } .^{2} \\
\text { Up to } 156,000 \\
129,000 \text { to } 135,000 \\
72,500 \text { to } 100,000 \\
40,000 \text { to } 111,000 \\
22,000 \text { to } 110,000 \\
46,000 \text { to } 74,000 \\
17,000 \text { to } 25,000\end{array}$ \\
\hline
\end{tabular}

1 Value depends on degree to which the rayon is oriented during manufacture.

Having achieved considerable success with respect to the production of fibers of high strength, many investigators have shifted their attention to the problem of trying to improve other mechanical properties of fibers. It appears that part of this trend has arisen from attempts to obtain fibers having "wool-like" qualities or properties. In view of this, it is pertinent to inquire into some of the properties which make wool different from other textile fibers. From the industrial point of view, the principal difference is found in the long-range elasticity of wool fibers; that is, their ability to recover from deformations of magnitudes considerably greater than those permitted by other types of fibers. The concept of orientation was effectively utilized in increasing the strength of the fiber, but, unfortunately, orientation is not directly correlated with long-range elasticity and, accordingly, the understanding of this unique mechanical property of wool must be sought in some other feature of its molecular structure. It is the purpose of this paper to examine certain aspects of the molecular structure from the point of view of their relations to long-range elasticity as well as to strength.

\section{MOLECULAR STRUCTURE OF WOOL}

Wool is composed principally of protein substance and, accordingly, it appears appropriate at this time to consider the factors which may influence the mechanical properties of fibrous proteins in general and wool in particular. 
Proteins are poly-condensation products in which the different amino acids are linked together to form the polypeptide chain, shown in the following scheme:

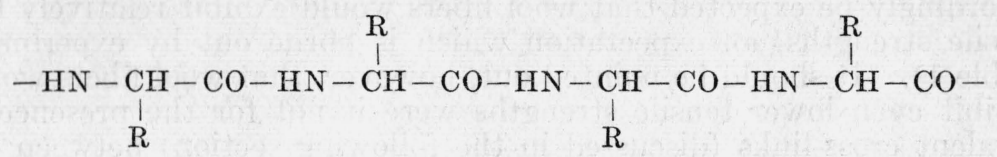

The mechanical properties of such chains can be considered, in general, to depend on the following four factors.

1. They exhibit great flexibility. This enables the protein molecule to assume a great number of possible configurations which could be either of the folded or spiral type. The importance of this molecular flexibility was first recognized by Astbury and Woods, who in their earlier work on wool [5] preferred a rather specific type of fold for the molecules of the fiber in the unstretched state, which they referred to as the $\alpha$-keratin configuration. The long-range extensibility of wool was ascribed to the opening of these folds into the more nearly straight chain configuration known as the $\beta$-keratin form. The original $\alpha$-keratin configuration has been shown to be untenable by Neurath [6], and a new type of fold has now been proposed by Astbury and Bell [7]. Such structures have been suggested on the basis of the $\mathrm{X}$-ray data, and should accordingly be found principally in the "crystalline" regions of the fiber. Since, as also is indicated by the X-ray diffraction patterns, these regions account for only a relatively small proportion of the total wool fiber, it appears that one may assume a more or less random type of folding in the "amorphous" regions which make up the bulk of the fiber. That a variety of configurations can exist is readily demonstrable by the construction of molecular scale models of polypeptide chains [8]. In considering the mechanical properties of wool, it seems therefore that more attention should be directed to the less organized regions of the fiber than has heretofore been done. It would be expected, for example, that the extension process might manifest itself to a greater extent in the amorphous rather than in the crystalline regions, and that the increase in crystallinity obtained on stretching a fiber may result from orientation of the unoriented regions as well as from changes in the already oriented portions of the fiber.

2. They possess a large number of the highly polar peptide linkages which can give rise to inter- and intra-molecular hydrogen bonding. While these bonds contribute much toward increasing the strength of the fiber, such close spacings of these groups along the molecular chain would be detrimental to other desirable fiber properties, were it not for another factor discussed in the following section. Carothers and Hill [9] have demonstrated that a preponderance of polar groups in synthetic materials renders linear polymers nonflexible and brittle.

3. They contain relatively large side chains ( $R$ groups in the scheme of the polypeptide chain) which prevent close packing of the protein molecules and thus decrease the extent to which hydrogen bonding can occur. In wool, nearly all of the constituent amino acids are of the type having large side chains, as shown by the data in table 2. From these data it can be estimated that close to 50 percent 
of the weight of wool is in the side chains. Close packing of molecular chains composed of such amino acids would indeed be difficult and intermolecular hydrogen bonding would be minimized. It would accordingly be expected that wool fibers would exhibit relatively low tensile strengths, an expectation which is borne out by experiment (table 1). It should be pointed out, however, that wool fibers would exhibit even lower tensile strengths were it not for the presence of covalent cross-links (discussed in the following section) between the molecular chains.

TABLe 2.-Amino-acid composition of wool

\begin{tabular}{|c|c|c|c|c|}
\hline Amino acid & $\begin{array}{l}\text { Present in } \\
\text { wool }\end{array}$ & Reference & $\begin{array}{l}\text { Grams of } \\
\text { residue per } \\
100 \text { grams of } \\
\text { wool }\end{array}$ & $\begin{array}{l}\text { Grams of } \\
\text { side-chain } \\
\text { per } 100 \text { grams } \\
\text { of wool }\end{array}$ \\
\hline 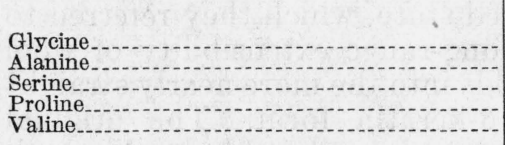 & $\begin{array}{r}\text { Percent } \\
6.5 \\
4.4 \\
9.41 \\
6.75 \\
4.72\end{array}$ & $\begin{array}{r}{[30]} \\
{[31,32]} \\
{[33]} \\
{[31]} \\
{[31]}\end{array}$ & $\begin{array}{r}\text { Grams } \\
4.94 \\
3.52 \\
7.80 \\
5.69 \\
3.99\end{array}$ & $\begin{array}{r}\text { Grams } \\
0.09 \\
.74 \\
2.76 \\
2.46 \\
1.73\end{array}$ \\
\hline $\begin{array}{l}\text { Threonine } \\
\text { Cystine/2 } \\
\text { Leucine isomers } \\
\text { Aspartic acid } \\
\text { Lysine }\end{array}$ & $\begin{array}{c}6.76 \\
\times 12.72 \\
11.3 \\
7.27 \\
3.3\end{array}$ & $\begin{array}{l}{[33]} \\
{[34]} \\
{[31]} \\
{[35]} \\
{[38]}\end{array}$ & $\begin{array}{r}5.74 \\
10.83 \\
9.75 \\
6.28 \\
2.89\end{array}$ & $\begin{array}{l}2.59 \\
4.89 \\
4.92 \\
3.22 \\
1.63\end{array}$ \\
\hline $\begin{array}{l}\text { Glutamic acid } \\
\text { Methionine } \\
\text { Histidine } \\
\text { Hydroxylysine } \\
\text { Phenylalanine }\end{array}$ & $\begin{array}{r}15.27 \\
0.71 \\
.7 \\
.21 \\
3.75\end{array}$ & $\begin{array}{l}{[35]} \\
{[31]} \\
{[30]} \\
36] \\
{[31]}\end{array}$ & $\begin{array}{r}13.40 \\
0.62 \\
.62 \\
.19 \\
3.34\end{array}$ & $\begin{array}{r}7.58 \\
0.36 \\
.37 \\
.11 \\
2.07\end{array}$ \\
\hline $\begin{array}{l}\text { Arginine } \\
\text { Tyrosine } \\
\text { Tryptophane.... }\end{array}$ & $\begin{array}{r}10.4 \\
5.8 \\
.7\end{array}$ & $\begin{array}{l}{[37]} \\
{[39]} \\
{[30]}\end{array}$ & $\begin{array}{r}9.33 \\
5.23 \\
.64\end{array}$ & $\begin{array}{r}5.97 \\
3.43 \\
.45\end{array}$ \\
\hline $\begin{array}{r}\text { Total } \\
\text { Ammonia N }\end{array}$ & $\begin{array}{r}110.67 \\
1.18\end{array}$ & [40] & $\begin{array}{r}94.80 \\
-.30\end{array}$ & $\begin{array}{l}45.37 \\
-.30\end{array}$ \\
\hline Total, corrected for ammonia $\mathrm{N}$ & & - & 94.50 & 45.07 \\
\hline
\end{tabular}

a Based on 3.55 percent total sulfur, subtracting methionine sulfur.

4. They exhibit association forces other than those contributed by hydrogen bonds. These may arise from various sources, but in the present discussion only those contributed by the amino acid cystine, which is found in unusually large amount in wool and other mammalian hair fibers, will be considered. Cystine, as first suggested by Astbury and Street [10], is responsible for a considerable amount of covalent cross-linking in the fiber. More recently, new chemical evidence [11] has been offered which supports the original conclusion of Astbury and Street. Wool may thus be considered a network of polypeptide chains linked together by the disulfide groups of the amino acid, cystine. Such a concept suggests that the role of cystine in wool must be an important one, and indeed it has been shown that many of the chemical, physical, and biological properties of wool protein [12] are dependent on the presence of these cross-links. The importance of these cross-links becomes even more apparent in the subsequent discussion in this paper concerning the experimental alteration or rupture of these links. 


\section{EXPERIMENTAL PROCEDURES}

\section{PREPARATION OF CHEMICALLY MODIFIED WOOLS}

The wool fibers used in the present study were a portion of a lot used in previous investigations in this laboratory and had been subjected to no chemical or mechanical treatment other than successive extraction with alcohol and ether followed by washing with water at $40^{\circ} \mathrm{C}[13]$.

The preparation of chemically modified wools in which the mode of linkage of the sulfur has been altered, without visibly affecting the fiber structure, has previously been described in detail [11]. The methods involve the reduction of wool with thioglycolic acid solution, followed by treatment of the reduced product with an alkyl halide. The reactions appear to affect only the disulfide groups of the cystine in wool and may be represented by the following equations:

$$
\begin{array}{r}
\mathrm{W}-\mathrm{S}-\mathrm{S}-\mathrm{W}+2 \mathrm{HS}-\mathrm{CH}_{2}-\mathrm{COOH} \longrightarrow 2 \mathrm{~W}-\mathrm{SH}+\left(\mathrm{S}-\mathrm{CH}_{2}-\mathrm{COOH}\right)_{2} \\
\mathrm{~W}-\mathrm{SH}+\mathrm{RX} \longrightarrow \mathrm{W}-\mathrm{SR}+\mathrm{HX} \\
2 \mathrm{~W}-\mathrm{SH}+\left(\mathrm{CH}_{2}\right) n \mathrm{X}_{2} \longrightarrow \mathrm{W}-\mathrm{S}-\left(\mathrm{CH}_{2}\right) n-\mathrm{S}-\mathrm{W}+2 \mathrm{HX},
\end{array}
$$

where W represents the portions of the wool connected by the disulfide groups, $\mathrm{R}$ represents an alkyl group, and $\mathrm{X}$, a halogen atom. Reactions 1 and 2 result in a permanent rupture of covalent cross linkages. Reactions 1 and 3 result in the formation of new crosslinks in which the sulfur atoms of the cystine are connected by short hydrocarbon chains.

\section{DETERMINATION OF ELASTICITY}

Measurements of the elastic properties were made on individual fibers by a modification of the method described earlier [13]. In this method the 30-percent index is the energy required to stretch a fiber to 30-percent elongation after a treatment, divided by the similar energy requirement prior to the treatment. This index is based on Speakman's demonstration that wool fibers can be elongated 30 percent without permanent deformation or weakening [14], if the duration of the strain is short. In the former investigations from this laboratory, however, the stress-strain characteristics of fibers were determined only during the extension process. In the present work, this procedure was modified so that measurements of the behavior of the fiber during its retraction could also be obtained.

The interpretation of these experiments involves four considerations, of which the first is the fraction of the original covalent bonds which has been altered. This may be inferred from the change in the percentage of cystine, which was determined by Sullivan's method [15] as used in this laboratory [16]. The cystine content of the untreated wool was 12 percent, and in the modified wools varied downward to 1 percent or less. The second consideration is the resistance to extension, which can be conveniently referred to as strength. The third is the completeness of recovery in the unloading, or retraction, part of the stress-strain cycle. The fourth is the time function, which involves both the rate of change of stress and the effect of internal structure on viscosity. Experiments are now in progress to analyze these kinetic relations more directly. 


\section{ELASTIC BEHAVIOR OF WOOL AND CHEMICALLY MODIFIED WOOLS}

Figure 1 shows the behavior of a typical wool fiber during two successive stress-strain determinations. The fiber was allowed to relax for approximately 24 hours between the first and second extensions. It is noteworthy that the entire stress-strain cycle is reproducible. This fact makes it possible to compare the stress-strain characteristics of a particular fiber in retraction as well as in extension, before and after a modification of its chemical structure.

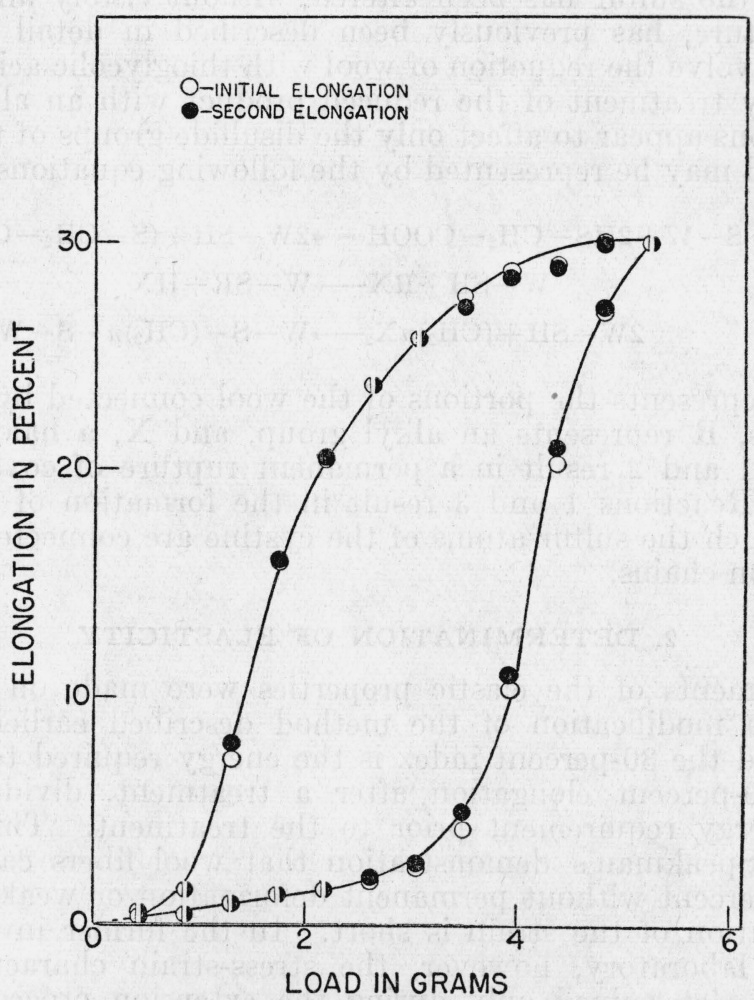

FIGURE 1.-Typical untreated wool fiber during two stress-strain cycles, separated by 24 hours.

30 -percent index $=0.99$.

When the cross-linkages have been permanently ruptured by the reduction process, followed by alkylation of the sulfhydryl groups with an alkyl monohalide of low molecular weight, such as methyl iodide or ethyl bromide, the resistance to extension is greatly altered, as shown in figure 2. Much less energy is required to elongate the fiber after the cross-links have been split, the 30-percent index dropping to the low value of 0.26 . In this material the S-shaped curve, characteristic of the original wool fiber and of other highly elastic materials, is not observed in extensions to only 30 percent, but can be demonstrated in experiments involving higher extensions. The whole scale of the relations of stress to strain has been shifted toward 
greater extensions for smaller forces. It should be added that the recovery from 30 -percent extension to the original length is complete and rapid.

If, after reduction, the cross-links are largely rebuilt by reoxidation of the sulfhydryl groups to the disulfide form, the wool recovers to a large extent its original properties, as shown in figure 3. The small discrepancy may arise either from the possibility that reoxidation has not been complete or that a few $\mathrm{SH}$ groups had reacted, during the reoxidation, with sulfhydryl groups other than those with which they were combined in the original fiber.

Alkylation of the reduced wool with an alkyl dihalide, such as methylene bromide or trimethylene bromide, results in the re-forma-

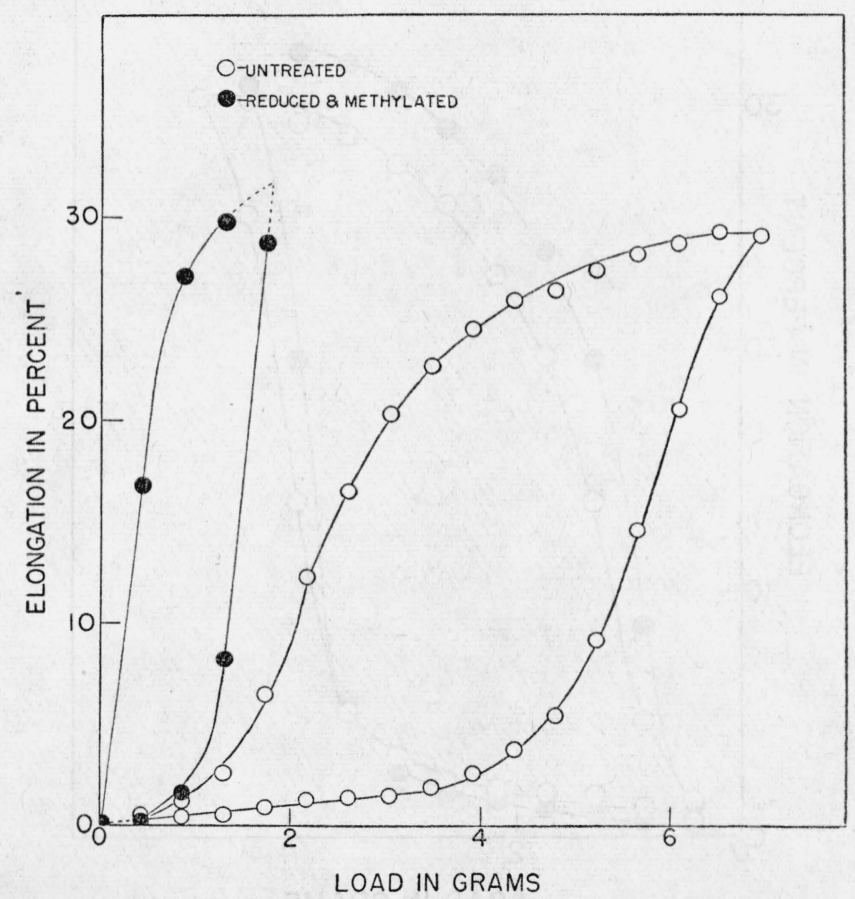

FIGURE 2.-Effect on the stress-strain cycle of opening 5/6ths of the cross-linkages by reduction and alkylation with methyl iodide.

30 -percent index $=0.26$.

tion of cross-linkages, but in this case, the disulfide linkage has been replaced by a bis-thioether linkage of the type $-\mathrm{S}\left(\mathrm{CH}_{2}\right)_{n} \mathrm{~S}-$. While the position of the stress-strain curve for the fiber after such treatment has been slightly shifted (fig. 4) from that of the original fiber, the shape of the curve and the recovery are very similar to those of the original fiber. A slight shift in the position of the curve is to be expected, since, obviously, the lengths of the cross-linkages have been increased and one would expect a slightly greater ease of extension of the fiber.

Figure 5 shows the behavior of wool after reduction followed by alkylation with a large alkyl monohalide, benzyl chloride. Although $463607-42-6$ 
in this case the covalent cross-linkages have been ruptured, the behavior of the fiber is very different from that of one in which covalent linkages have been ruptured by reduction followed by alkylation with small alkyl monohalides such as methyl iodide or ethyl bromide. As will be noted, the benzylated wool shows a considerably greater resistance to extension than the methylated wool (compare fig. 2). After sufficient load has been applied, the extension curve rises steeply

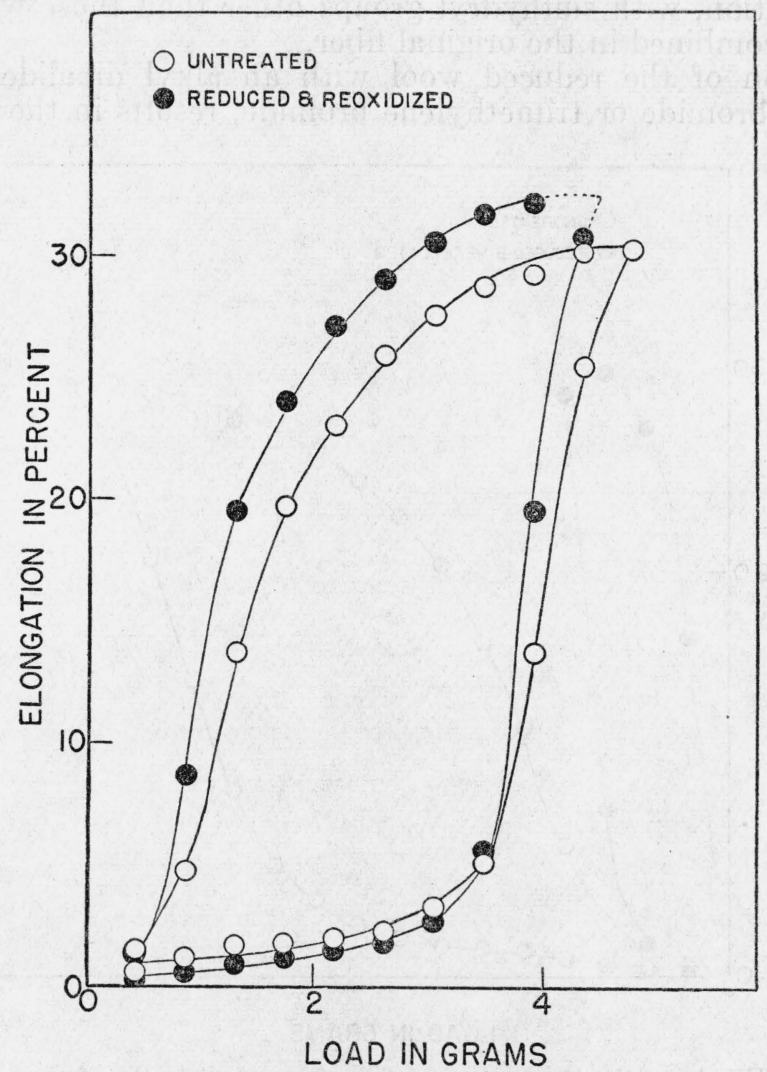

FIGURE 3.-Effect on the stress-strain cycle of reduction of one-half of the crosslinkages, followed by rebuilding by oxidation with oxygen.

30 -percent index $=0.96$.

with respect to the load axis. The relations with respect to time cannot be presented completely in this type of experiment, but it can be stated that the rate of flow is less than that of methylated wool. On removal of the load there appears to be a great resistance to the contraction of the fiber to its original length. Whereas in the other experiments presented here the elastic recovery was rapid and nearly complete within 1 minute after the removal of the last unit of load, in this experiment with benzylated wool retraction required 3 hours to reach an equal degree of completeness. This is indicated by the dotted line in figure 5. The behavior is such as to suggest that while covalent cross-linkages have been broken, some interaction between 
the polypeptide chains still exists. It may be that benzyl groupson adjacent sulfur atoms exhibit mutual interaction of a van der Waals type, or that thereis an attraction between benzyl groups and a portion of a neighboring polypeptide chain. At the point of maximum extension the benzyl groups appear to form new interactions which resist the tendency of the fiber to return to its original length. An alternative explanation could be that the large volume of the benzyl group increases the energy of activation required for flow [17]. A

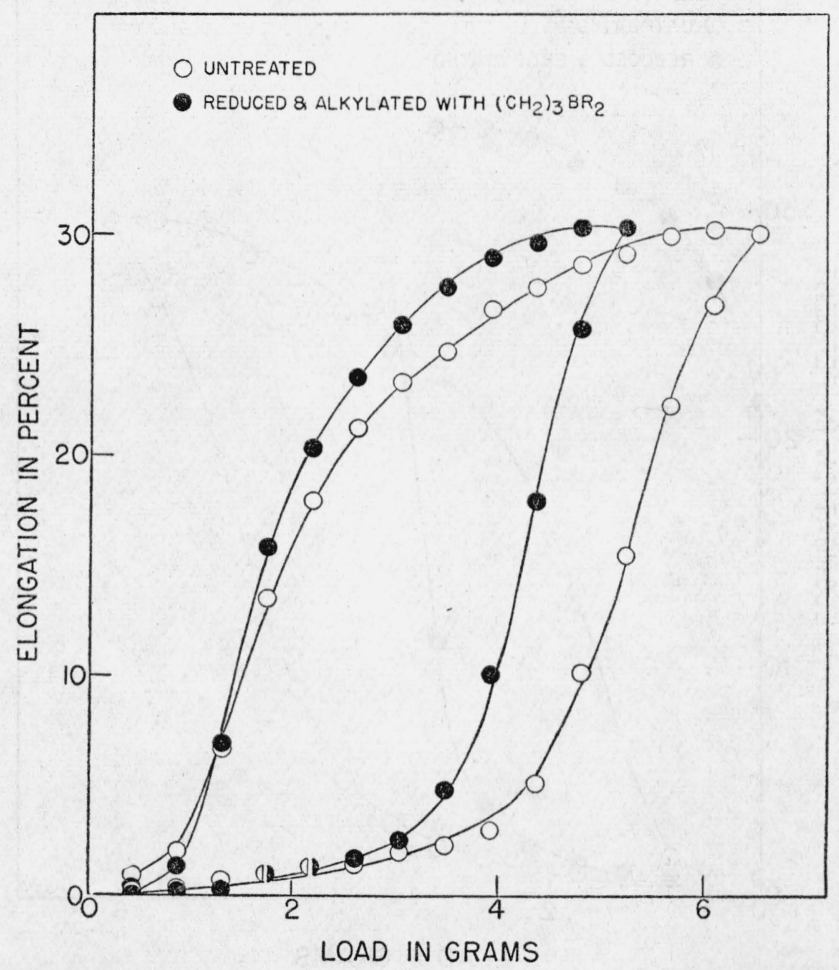

FIGURE 4.-Effect on the stress-strain cycle of rebuilding of 5/6ths of the crosslinkages as bis-thioethers by reduction and alkylation with trimethylene bromide.

30 -percent index $=0.82$.

quantitative investigation of the effects of both the size of the substituent and the temperature upon the flow is necessary for a more detailed explanation of these phenomena.

\section{ANALOGY BETWEEN WOOL AND RUBBER}

The results of the present investigation suggest that in many ways wool is quite analogous to rubber, and indeed in some respects may serve as a useful model for explaining certain properties of the latter.

It appears that the long-range extensibilities of both rubber and wool depend on the fact that both have configurations which can be straightened out during the stretching process [18]. Both wool and 
rubber are largely amorphous in the unstretched state although in this state the former appears to contain a somewhat higher proportion of a crystalline phase. As indicated by X-ray studies [19,4], the amount of this phase is greatly increased during the process of stretching.

Probably the most interesting analogy, however, is found in comparing the properties of raw and vulcanized rubber with those of wool, before and after the rupture of its disulfide groups. ${ }^{3}$ While it is

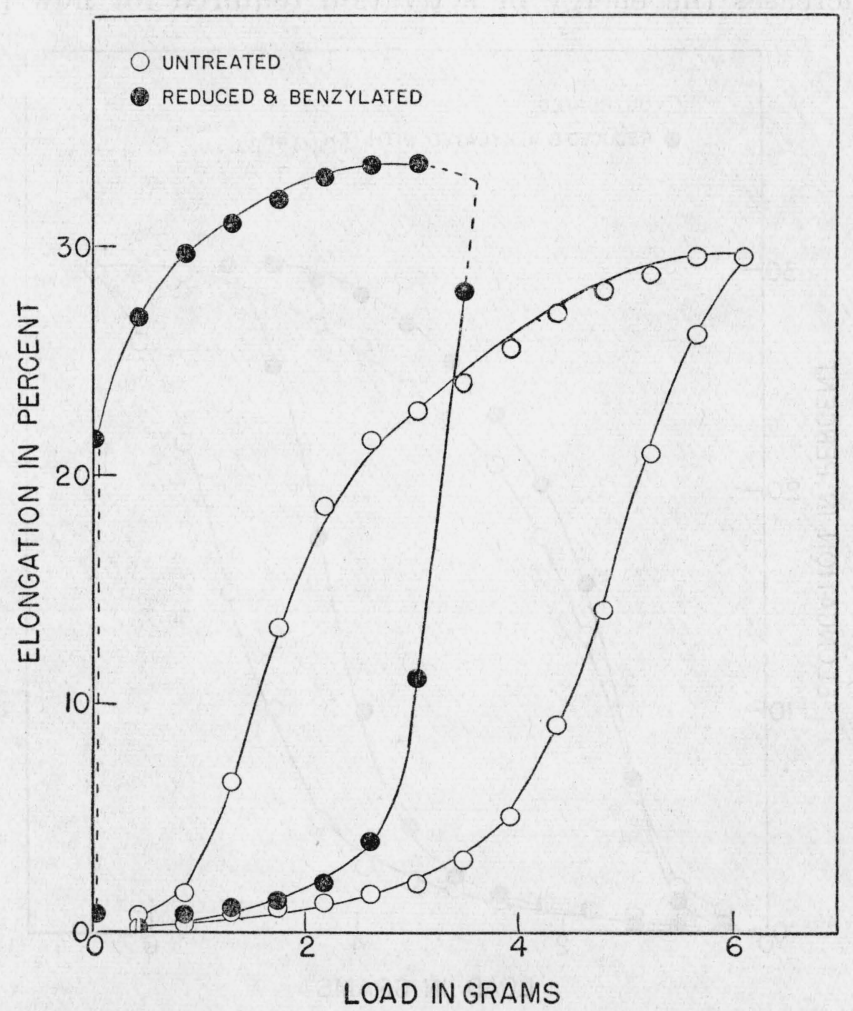

Figure 5.-Effect on the stress-strain cycle of opening of 5/6ths of the cross-linkages by reduction and alkylation with benzyl chloride.

30 -percent index $=0.65$. The dotted line along the ordinate axis indicates a slow completion of the cycle by contraction at low stress.

generally assumed that vulcanization of rubber involves a cross-linking process $[21,18]$, it appears that proof of the chemical structure of the cross-links is lacking. On the other hand, it now seems well established that in wool the disulfide groups of the amino acid cystine do form cross-links between molecular chains. Thus the difference in behavior of wools before and after rupturing these cross-links serves as a useful model for rubber, and indeed, as is seen in the following discussion, lends considerable support to the hypothesis of crosslinking in vulcanized rubber.

A consideration of the chemistry of the wool fiber during the course of its production brings forth some additional points relative to this

${ }^{3}$ Astbury and Dickinson have suggested that keratin is a "vulcanized" protein [20]. 
discussion. A growing wool fiber consists of a root and a shaft, the former being the living region situated beneath the surface of the skin, whereas the latter is the nonliving portion extending above the surface. Examination of the root portion reveals that it is principally a gelatinous protein mass containing a relatively large amount of sulfhydryl groups [22]. In other words, it would appear that in the synthesis of wool, cysteine rather than cystine is synthesized into the polypeptide chains. The material in the root of the hair is in some ways comparable to rubber latex. When the hair cells die, oxidation presumably takes place, since the sulfhydryl groups are completely converted to disulfide groups. At this stage, the soft, plastic material of the root becomes the tough, elastic wool fiber. This, in a sense, can be considered to be analogous to the vulcanization process.

The solubility and swelling properties of both wool and rubber serve to emphasize the similarity in the physical structures of these two materials. Untreated wool fibers swell appreciably in a variety of aqueous solutions but are definitely insoluble in the usual protein solvents. Rupture of the disulfide cross-links yields a product which is readily soluble, for example in alkaline solutions, but the original insolubility is restored after re-formation of these links [11]. Similarly, it can be shown that whereas unvulcanized rubber is soluble in a variety of organic solvents, vulcanization renders the material insoluble in the same solvents. With unvulcanized rubber, it is possible to form a clear solution of the rubber in a solvent, but the vulcanized rubber appears only to swell and form a gel-like structure [23].

Since, in the absence of imposed strain, neither material exists in the fully extended form, there can be little close packing and accordingly there will be relatively few points of interaction as compared with highly oriented materials such as the cellulose, silk, or nylon fibers. As would be expected, the tensile strengths, or, more generally, the resistance to further extension, of such normally unoriented materials is always low. Within the range from zero strength to these low maxima, however, resistance to extension is sensitively related to the frequency and intensity of molecular interactions. This is readily demonstrated by the stress-strain behavior of unvulcanized rubber, or of wool in which practically all of the disulfide crosslinkages have been ruptured. However, when rubber is vulcanized or the cross-links are introduced into reduced wool, similar changes in the mechanical properties of both materials are observed, as shown in figures 2 and 6 . It is seen that with cross-linking the materials become stronger, and their moduli of elasticity become higher. In addition, they show lower extensibilities at break. Modified wool fibers in which most of the cross-linkages have been ruptured may be extended more than 100 percent when stretched in water, whereas untreated wool fibers can be extended only about 50 to 60 percent before breaking. A representative sample of unvulcanized rubber had an elongation of 1,200 percent at break whereas after vulcanization the elongation at break of a similar sample was only 700 percent [25].

There is, however, one principal difference between the two types of molecules. Rubber is practically entirely hydrocarbon and accordingly exhibits only low-order molecular cohesion or interactions whereas wool contains a large proportion of highly polar groups ca- 
pable of forming relatively strong molecular interactions. For this reason, the sensitivity of rubber to temperature is not shared by dry wool. On the other hand, the mechanical properties of the latter are greatly affected by moisture, which swells the protein and presumably decreases intermolecular cohesion. Thus it is found that the influence of heat on the mechanical behavior of rubber is very similar to the influence of moisture on the behavior of wool.

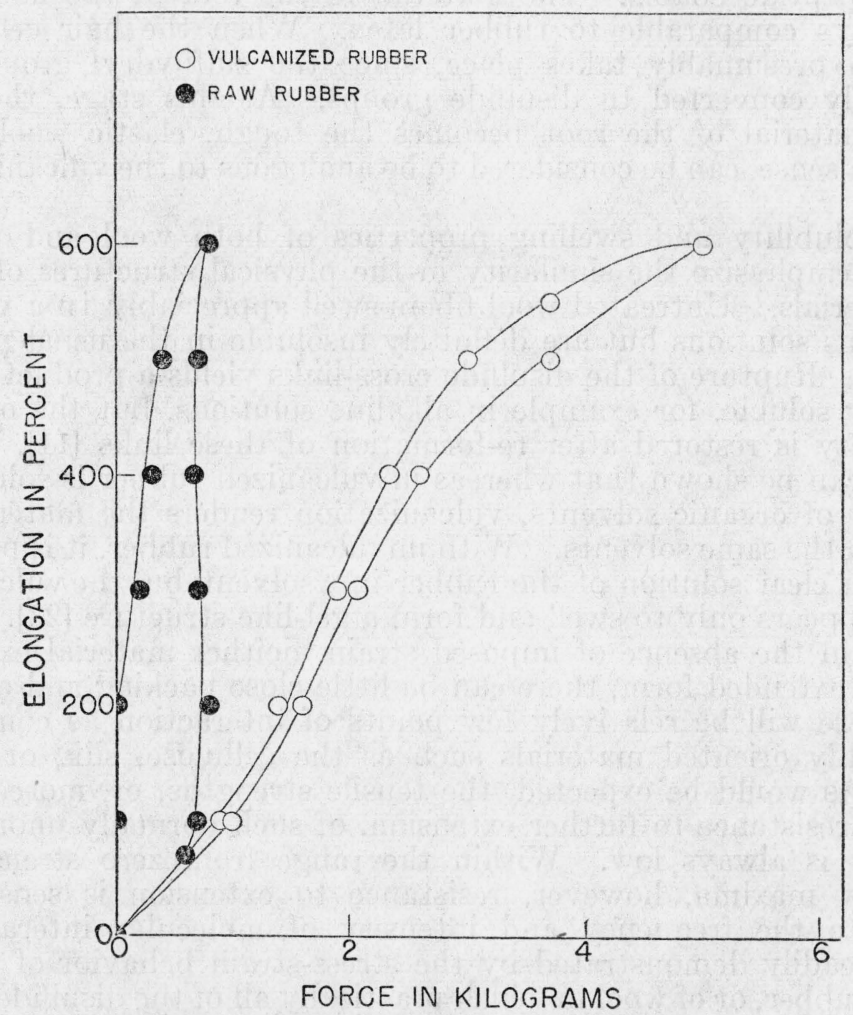

FIGURE 6.-Stress-strain cycles of a sample of rubber before and after vulcanization

Data from Hock and Bostroem [24].

\section{CONCLUSION}

These experiments and comparisons lead to a better understanding of the molecular basis of the elastic properties of wool. The longrange elastic characteristics are not dependent on the presence of crosslinks, but probably result from the ability of flexible chain molecules to contract from the less probable stretched state to a more random form. Meyer [26] and Mark [27] have reviewed the evidence for this view of the origin of long-range elasticity. The function of cross-links is to strengthen the materials and suppress plastic flow. The introduction of a higher proportion of cross-links would decrease the flexibility and reduce the range of elasticity, as illustrated by the properties of highly vulcanized rubber (ebonite). This analysis of the mechanical properties of these systems leads to the conclusion that a 
textile fiber having desirable long-range elastic characteristics must consist of flexible chains reinforced with a proper balance of crosslinks. ${ }^{4}$

The influence of covalent chemical cross-linking on the properties of wool, rubber, and other high-polymer systems is now receiving considerable attention. As far as the authors are aware, wool is not only the first substance in which covalent cross-linking has been established, but also is the only one in which the cross-links can be quantitatively ruptured and rebuilt at will. It may thus serve as an excellent model for many other high-polymeric systems.

\section{REFERENCES}

[1] P. Scherrer, Göttinger Nachr. 1918, 98.

[2] R. O. Herzog and W. Jancke, Z. Kaiser Wilhelm Ges. (1921); Z. physik. Chem. [A] 139, 235 (1920).

[3] K. H. Meyer, and H. Mark, Ber. deut. Chem. Ges. 61, 1932 (1928).

[4] W. T. Astbury and H. J. Woods, Nature 126, 913 (1930).

[5] W. T. Astbury and H. J. Woods, Phil. Trans. Roy. Soc. (London) [A] 232, $333(1933)$.

[6] H. Neurath, J. Phys. Chem. 44, 296 (1940).

[7] W. T. Astbury and F. O. Bell, Nature 14\%, 696 (1941).

[8] H. S. Taylor, Proc. Am. Philos. Soc. 85, 1 (1941).

[9] W. H. Carothers and J. W. Hill. J. Am. Chem. Soc. 54, 1579 (1932).

[10] W. T. Astbury and A. Street, Phil. Trans. Roy. Soc. (London) [A] 230, 333 (1931).

[11] W. I. Patterson, W. B. Geiger, L. R. Mizell, and M. Harris, J. Research NBS 27, 89 (1941) RP1405; Am. Dyestuff Rptr. 30, No. 17, 425-430; Textile Research 11, 379 (1941).

[12] W. B. Geiger, W. I. Patterson, L. R. Mizell, and M. Harris, J. Research NBS 27, 459 (1941) RP1433; Am. Dyestuff Rptr. 30, No. 24, 659 (1941). M. Harris, Textile Research 12, 19 (1941).

[13] A. M. Sookne and M. Harris, J. Research NBS 19, 535 (1937) RP1043; Am. Dyestuff Rptr. 26, No. 22, 659-669 (1937).

[14] J. B. Speakman, Proc. Roy. Soc. (London) [B] 103, 377 (1928).

[15] M. X. Sullivan, Public Health Reports 86 (1930).

[16] M. Harris and A. L. Smith, J. Research NBS 18, 623 (1937) RP998; Am. Dyestuff Rptr. 26, No. 15, 413-415 (1937).

[17] W. Kauzman and H. Eyring, J. Am. Chem. Soc. 62, 3113 (1940).

[18] R. Houwink, Elasticity, Plasticity, and Structure of Matter, Cambridge University Press (1937).

[19] J. R. Katz, Naturwissenschaften 13, 411 (1925).

[20] W. T. Astbury and S. Dickinson, Nature 135, 95 (1935).

[21] I. Williams, Theories and Phenomena of Vulcanization, in C. C. Davis and J. T. Blake's The Chemistry and Technology of Rubber, p. 237 (Reinhold Publishing Corp., New York, N. Y. 1937).

[22] C. W. Hock, R. C. Ramsay, and M. Harris, J. Research NBS 2\%, 181 (1941) RP1412; Am. Dyestuff Rptr. 30, No. 18, 449-456 (1941); Textile Research 11, 415-428 (1941).

[23] W. F. Busse, p. 181 in C. C. Davis and J. T. Blake's The Chemistry and Technology of Rubber (Reinhold Publishing Corp. New York, N. Y., 1937).

[24] L. Hock and S. Bostroem, Kautschuk 2, 132 (1926).

4 In this connection, it is interesting to note that the absence of any appreciable amount of covalent cross linkings undoubtedly accounts to a large extent for the low tensile strengths, especially in the wet state, of regenerated protein fibers made from casein, soybean protein, etc. Silk fibers, on the other hand, which apparently do not contain any covalent cross-linking exhibit very high tensile strengths. Examination of their chemical constitutions reveals that nearly two-thirds of the amino acid content is accounted for by glycine and alanine, compounds which have only hydrogen and methyl groups as side chains [28]. From the available analytical figures it is found that only 36 percent of the weight of silk is in the side chains, in contrast to 48 percent for wool and 54 percent for casein. It follows that while in wool the chain weight is to the side chain weight as 1 to 1 , in silk this ratio is nearly 2 to 1 . Polypeptide chains of silk may thus be considered to be significantly more bare than those of wool, making possible a considerable amount of close packing and interchain hydrogen bonding, which would account for the high observed strengths. Comparison of the X-ray diagrams of silk and of wool [29] shows a much higher "degree of crystallization" in the silk. 
[25] P. Rosbaud and E. Schmid, Z. tech. Physik 9, 98 (1928); G. S. Whitby and M. Katz, Ind. Eng. Chem. 25, 1204, 1338 (1933) cited from: L. A. Wood, NBS Circular C427 (1940).

[26] K. H. Meyer, Chem. Rev. 25, 137 (1939).

[27] H. Mark, Chem. Rev. 25, 121 (1939).

[28] M. Bergmann, and C. Neimann, J. Biol. Chem. 115, 77 (1936); J. Biol. Chem. 118, 301 (1937).

[29] W. T. Astbury, Fundamentals of Fiber Structure (Oxford Press, London, 1933).

[30] R. J. Block, J. Biol. Chem. 128, 181 (1939).

[31] A. J. P. Martin and R. L. M. Synge, Biochem. J. 35, 91 (1941).

[32] E. Abderhalden and A. Voitinovici, Z. physiol. Chem. 52, 348 (1907).

[33] A. J. P. Martin and R. L. M. Synge, Biochem. J. 35, 294 (1941).

[34] J. McCallum, unpublished data in this laboratory.

[35] J. B. Speakman and F. Townend, Nature 139, 411 (1937).

[36] D. D. van Slyke, A. Hiller, and D. A. MacFayden, J. Biol. Chem. 141, 681 (1941).

[37] H. B. Vickery, J. Biol. Chem. 132, 325 (1940).

[38] H. A. Rutherford, M. Harris, and A. L. Smith, J. Research NBS 19, 467 (1937) RP1038.

[39] H. A. Rutherford and M. Harris, cited from J. Steinhardt and M. Harris, J. Research NBS 24, 335 (1940) RP1286.

[40] J. Steinhardt, unpublished data in this laboratory.

Washington, February 2, 1942. 